Resenha de: MEYER, Dagmar Estermann; PARAÍSO, Marlucy Alves (Orgs.). Metodologias de pesquisa pós-críticas em educação. Belo Horizonte: Mazza Edições, 2012.

\title{
CONCEITOS E PRÁTICAS PARA PESQUISAS CONTEMPORÂNEAS: ALGUMAS PALAVRAS SOBRE A OBRA METODOLOGIAS DE PESQUISAS PÓS-CRÍTICAS EM EDUCAÇÃO
}

A obra Metodologias de pesquisas pós-críticas em educação, organizada pelas Doutoras Dagmar Estermann Meyer e Marlucy Alves Paraíso, apresenta ao leitor, de forma clara e agradável de ler, como pesquisadores, ancorados em perspectivas teóricas pós-críticas, (re)constituíram conceituações, estratégias de análise e produção de conhecimentos, através da organização e realização de suas pesquisas.

As abordagens teóricas conhecidas como pós-críticas, tais como pós-estruturalismo, pós-modernismo, pós-colonialismo, pós-gênero, pósfeminismo, estudos culturais, estudos de gênero, estudos étnicos e raciais, estudos queer, multiculturalismo e pensamento da diferença, destacadas pelas autoras, tencionaram o campo das teorizações educacionais através da problematização de conceitos como: sujeito, linguagem, verdade e poder, dentre outros. Os pesquisadores ligados a essas linhas fomentaram a produção de diferenciados saberes e de outras formas de pesquisar, o que a obra em questão visibiliza. Destacamos que, em tais abordagens teórico-metodológicas, pressupostos e procedimentos são selecionados e

\footnotetext{
* Doutoranda em Educação pela Universidade Federal do Rio Grande do Sul (UFRGS); Docente da Rede Municipal de Ensino de Porto Alegre. E-mail: julivargas10@hotmail.com

* Doutora em Educação pela Universidade Federal do Rio Grande do Sul (UFRGS); Professora convidada da Faculdade de Educação da Universidade Federal do Rio Grande do Sul (UFRGS). E-mail: mlxavier@uol.com.br
} 
organizados em razão da especificidade de cada investigação. Logo, é importante lembrar que, para aqueles que se filiam às perspectivas teóricas pós-críticas nas suas produções, as metodologias de pesquisa estão imbricadas tanto na composição do problema de investigação, como na construção de estratégias e, ainda, nos modos de constituição/interpretação dos dados analíticos de cada estudo.

O aporte nas perspectivas teóricas pós-críticas e os movimentos de (re)construção de métodos e (re)significação de procedimentos para a efetividade de suas investigações podem ser entendidos como frentes que ligam os estudos apresentados na referida obra. De modo semelhante, os conceitos, em consonância com as perspectivas teóricas utilizadas pelos autores, são compreendidos como ferramentas para operar e conduzir suas investigações. Alinhadas por essas premissas, distintas metodologias são apresentadas ao leitor na descrição de estudos acerca de artefatos culturais, tais como cinema, televisão, revistas, músicas e internet, currículos escolares, currículos culturais não escolares e, ainda, sobre políticas públicas focadas na inclusão social.

A obra em questão é composta de 13 artigos que teorizam o fazer metodológico empreendido por pesquisadores de temáticas relacionadas às áreas de educação e saúde. Tais pesquisadores são ligados aos grupos de pesquisa GECC/FAE/UFMG (Grupo de Estudos e Pesquisas sobre Currículos e Culturas da Faculdade de Educação da Universidade Federal de Minas Gerais) e GEERGE/FACED/UFRGS (Grupo de Estudos em Educação e Relações de Gênero da Faculdade de Educação da Universidade Federal do Rio Grande do Sul).

Vale destacar que Dagmar Meyer, integrante do GEERGE, atua como professora colaboradora convidada no Programa de PósGraduação em Educação e também no Programa de Pós-Graduação em Saúde Coletiva, ambos da Universidade Federal do Rio Grande do Sul. Dagmar Meyer tem orientado estudos e investigações nas áreas de educação, sexualidade e relações de gênero; políticas para família, gênero e geração; políticas públicas de inclusão social, gênero e sexualidade e também em práticas pedagógicas em saúde. Seus interesses de pesquisa focalizam, também, a discussão da politização contemporânea do feminino e da maternidade.

Já Marlucy Paraíso, coordenadora do GECC, atua como professora da Faculdade de Educação da Universidade Federal de Minas Gerais 
e também no Programa de Pós-Graduação em Educação da mesma instituição. Tem orientado teses e dissertações que associam o campo do currículo a temas tais como diferenças, culturas, gênero, outros artefatos tecnoculturais e mídia. Ainda é importante referir que seus trabalhos de ensino, pesquisa, extensão e orientação têm como foco os currículos escolares e não escolares.

Os primeiros artigos da obra, de autoria das organizadoras, discorrem acerca das perspectivas teóricas pós-críticas e pós-estruturalistas em educação e das abordagens metodológicas que são constituídas em consonância com tais perspectivas. Marlucy Paraíso, no primeiro artigo, discute como distintas correntes teóricas pós-críticas em educação contribuem para a constituição das pesquisas realizadas sobre as temáticas de educação e currículo, organizadas sob sua orientação no Programa de Pós-Graduação em Educação da Universidade Federal de Minas Gerais. Para tanto, a autora apresenta premissas e pressupostos que norteiam os estudos realizados a partir de tais perspectivas, a exemplo das mudanças significativas nas condições sociais, nas relações culturais e nas racionalidades ocorridas na atualidade. Tais mudanças implicam transformações no campo educacional e, por conseguinte, nas estratégias estabelecidas em tal campo. Conceitos como regimes de verdade, modos de subjetivação, relações de poder, diferença e multiplicidade, discurso como producente de práticas, objetos e sujeitos e a compreensão do próprio sujeito como efeito de linguagens são também pressupostos e premissas apresentados pela autora, que enfatiza, ainda, que as pesquisas constituídas pelo aporte das teorizações acima destacadas devem posicionar-se como rigorosas e inventivas na busca de "pensar o impensado".

No segundo capítulo, Dagmar Meyer apresenta ao leitor, através da descrição de experiências investigativas realizadas sob sua orientação, encaminhamentos metodológicos que analisam e problematizam, de modo especial, a produtividade do conceito de gênero em temáticas tais como políticas públicas e/ou ações programáticas de inclusão e desenvolvimento social nos âmbitos da educação e da saúde. Vale destacar que tais pesquisas situam-se, de acordo com a autora, na interface das perspectivas dos Estudos Culturais e os Estudos de Gênero e das conceituações/ ferramentas alinhadas com as teorizações foucaultianas. De modo semelhante à autora do capítulo anterior, Meyer destaca determinados pressupostos que guiam algumas das pesquisas por ela orientadas, a saber: a lin- 
guagem como produtora das relações estabelecidas entre a cultura, corpo, conhecimento e poder; a educação como um conjunto de processos pelos quais os indivíduos tornam-se sujeitos de uma cultura; a interpretação e a problematização de determinadas políticas como linguagens e, ainda, a compreensão de artefatos culturais e tecnologias de poder como elementos que incidem nos modos de subjetivação dos sujeitos e, por conseguinte, nas formas de organização das populações. Por fim, a autora destaca o entendimento do conceito de gênero como organizador social/cultural que marca e distingue os corpos e sujeitos femininos e masculinos, muitas vezes, em articulação com os demais marcadores, tais como classe, raça/etnia e sexualidade.

O uso da etnografia como ferramenta metodológica de pesquisa é apresentado nos três capítulos seguintes da obra. No terceiro capítulo, os autores Carin Klein e José Damico discorrem sobre o uso de estratégias etnográficas de investigação para o desenvolvimento de seus estudos de doutorado. Enquanto Klein destaca a análise das ações políticas da Primeira Infância Melhor (PIM/RS), na Vila Getúlio Vargas (Canoas, RS), compreendendo-as como modos de enunciação, educação e regulamentação das condutas de mulheres pobres no exercício da maternidade, Damico analisa as ações do Programa Nacional de Segurança Pública e Cidadania (Pronasci) organizadas no bairro Guajuviras (Canoas, RS). Tais ações são compreendidas pelo autor como modos de governamento da juventude fomentados pelas políticas de segurança pública. Vale referir que, para ambos os autores, a incorporação do método etnográfico em uma investigação está implicada na escolha dos referenciais teóricos, na organização dos problemas, das questões de estudo e dos procedimentos de produção dos dados empíricos. Destacam ainda que a inserção do investigador em relação à realidade pesquisada e as análises por ele constituídas são ações-chave para a realização de pesquisas alinhadas ao método em questão. Ao longo do capítulo, os autores descrevem como se valeram, na realização de suas pesquisas, de procedimentos tais como exame de documentos, observação participante, organização de diário de campo, entrevistas e grupos de discussão. Por fim, ambos os autores apresentam ao leitor suas considerações acerca das temáticas estudadas.

A etnografia e alguns de seus procedimentos, conforme as autoras Patrícia Balestrin e Rosângela Soares, podem ser utilizados também para investigações que demandem análise de imagens, a exemplo de pro- 
gramas de televisão ou produções cinematográficas. Tais autoras discorrem, no quarto capítulo da obra, sobre a "etnografia de tela", como recurso metodológico. Valendo-se das palavras de Rial, as autoras definem a "etnografia de tela" como uma metodologia que busca aplicar estratégias de análise etnográfica, aliando-as às ferramentas próprias da análise cinematográfica. Dessa forma, o longo período de contato com o filme, os registros em diário de campo acerca dos pontos potenciais para análise investigativa e a escolha de determinadas cenas para a realização do estudo são procedimentos descritos pelas autoras como fundamentais para a articulação de uma etnografia de tela. Além desses, a observação dos planos de filmagem utilizados, das trilhas sonoras, da organização da iluminação e itens da análise cinematográfica também compõe a metodologia da etnografia de tela.

Shirley Sales apresenta, no quinto capítulo da obra, de que modo estratégias etnográficas, em conjunto com a análise do discurso em perspectiva foucaultiana, constituíram as estratégias metodológicas de sua investigação de doutorado. Em tal estudo, a autora buscou analisar o processo de produção de subjetividades juvenis na contemporaneidade, na interface entre o discurso de um site de relacionamento social (Orkut) e o currículo de uma escola pública de ensino médio. Por transitar pelos campos do espaço escolar e do ciberespaço, a autora vale-se de ferramentas da etnografia educacional e da netnografia a fim de empreender seu estudo. Logo, é possível destacar a inserção, a observação participante e a realização de entrevistas, por parte da investigadora, em ambos os espaços de análise, ou seja, a escola e a rede social em questão. Encerrando o capítulo, a autora destaca que a articulação empreendida entre as ferramentas teórico-metodológicas elencadas corroborou a compreensão/problematização de conceitos como fluidez, multiplicidade e provisoriedade, os quais atravessam a produção de subjetividades dos jovens por ela estudados.

Estratégias analíticas realizadas no ambiente virtual também são tema do sexto capítulo da obra, de autoria de Jeane Félix. Descrevendo sua investigação de doutorado, na qual buscou compreender as vivências, bem como os sentidos a elas atribuídos por jovens que vivem com HIV, a autora destaca as entrevistas narrativas on-line como estratégia metodológica. Para seu intuito, a autora encaminhou, para 15 comunidades virtuais de uma rede social (Orkut) e também para a Rede Nacional de 
Adolescentes e Jovens vivendo com a HIV/AIDS (RNAJVHA), um convite para a participação em sua pesquisa. Tais entrevistas foram realizadas por meio de ferramentas de comunicação instantâneas (MSN Messenger e Gtalk), com jovens que vivem com HIV/AIDS. É interessante destacar que as entrevistas narrativas on-line demandaram da autora disposição para realizar conversas nos momentos mais propícios aos participantes da investigação, o que, por vezes, ocorria no período da madrugada. $\mathrm{O}$ envolvimento e habilidade com as tecnologias virtuais, bem como a necessária flexibilidade no seu roteiro de entrevista, a fim de atender a individualidade dos participantes, são apontadas pela autora como fundamentais para a articulação de seu estudo. Encerrando o capítulo, Félix destaca a possibilidade de contatar, por diversas vezes, com sujeitos de diferentes (e distantes) localidades, a flexibilidade de horário e o favorecimento do anonimato dos participantes como características que potencializam o uso das entrevistas narrativas on-line como recurso metodológico.

Marlécio Maknamara, autor do sétimo capítulo da referida obra, apresenta ao leitor a metodologia empregada por ele para a análise de discursos presentes em músicas do estilo denominado como forró eletrônico. ${ }^{1}$ Ao perceber a constante presença do referido estilo musical no ambiente escolar, o autor buscou compreender como músicas vinculadas a esse ambiente operavam como um "currículo" que produz e ensina sobre temáticas como nordestinidade e gênero, entre outras. Maknamara empreendeu a metodologia de análise discursiva de inspiração pós-estruturalista, apoiado principalmente em Michel Foucault, analisando as músicas de forró eletrônico como discursos que operavam na produção de subjetividades daqueles que as escutavam. A imersão no material de análise, ouvindo repetidas vezes as músicas escolhidas, a compreensão do cenário midiático da produção musical e a articulação dos conceitos/ferramentas escolhidos, revisitando, de modo constante, as referências teóricas elencadas, são passos descritos pelo autor como necessários para a produção de sua investigação.

$\mathrm{O}$ uso das entrevistas narrativas como ferramenta metodológica em uma pesquisa inserida na perspectiva etnográfica é o tema abordado por Sandra Andrade, no capítulo que segue. Apoiada em Foucault, Larrosa e Arfuch, a autora analisou relações entre escolarização, juventudes e processos de exclusão, através de entrevistas narrativas protagonizadas com alunos da modalidade EJA. É interessante destacar que Andrade 
aproxima as entrevistas narrativas individuais às "discussões em grupo, ou entrevistas narrativas em grupo", sem pontuar uma diferenciação rígida entre as diferentes estratégias.

O grupo focal, entendido como o espaço para que o pesquisador constitua dados analíticos a partir das interações e discussões entre participantes frente a um tema comum, é o tema abordado por Maria Cláudia Dal'Igna, no nono capítulo da obra. A autora descreve a metodologia de sua pesquisa de doutorado, na qual buscou compreender e problematizar as relações entre família e escola. Apesar de também valer-se de entrevistas como ferramenta metodológica para sua investigação, a autora destaca como o trabalho com o grupo focal fomentou a organização de sua pesquisa e (des)estabilizou o seu próprio papel de pesquisadora, uma vez que sua investigação ocorreu em seu ambiente profissional, e, dessa forma, muitas das participantes não lhe eram desconhecidas. É possível pensar que o destaque dado pela autora às questões éticas da pesquisa esteja relacionado tanto à escolha das perspectivas pós-estruturalistas que subsidiam sua investigação, bem como ao vínculo preexistente entre a investigadora e os sujeitos investigados.

Sob o título de uma metodologia alquimista, a autora Lívia Cardoso articula elementos da etnografia pós-moderna e da análise de discurso foucaultiana, considerando a própria ciência como um artefato cultural permeável a conceituações e problematizações de discursos de diversificados campos de saber. Inspirada em procedimentos arquegenealógicos e com o objetivo de compreender como são fabricados alunos e professores frente às discursividades circulantes em aulas experimentais de Ciências, a autora realizou a análise de currículo e das práticas de tal disciplina ao longo do ano letivo de uma escola na qual a experimentação era ferramenta pedagógica utilizada pelos professores da referida disciplina. De acordo com Cardoso, tais discursividades acabam por naturalizar e legitimar verdades e discursos, constituindo e governando sujeitos.

A metodologia queer é o tema do capítulo de autoria de Cristina Reis. Neste, a autora descreve como constituiu sua investigação de mestrado, na qual analisou a constituição generificada de alunos sob as práticas de um currículo escolar. Aproximando-se de Judith Butler e Tomás Tadeu da Silva, a autora compreende o conceito de gênero como marca reguladora de corpos e ações dos sujeitos, e o currículo, como um território de disputa no qual discursos e significados são produzidos e contesta- 
dos. Vale destacar que os estudos queer surgem nos anos de 1980 alinhados às lutas sociais dos movimentos gays e lésbicos, os quais contestavam a fixação das identidades sexuais e de gênero, e, ainda, os discursos pautados na heteronormatividade como regulatórios das relações entre homens e mulheres. Valendo-se de procedimentos etnográficos tais como observações, registros em diário de campo, conversas informais e consultas de documentos, a autora analisou práticas curriculares como hierarquizadoras, nomeadoras e classificatórias de corpos-meninos-alunos, problematizando as produções regulatórias sobre eles e, ainda, a constituição binária dos corpos sexuados.

A análise de imagens é a ferramenta metodológica descrita por Maria Simone Schwengber no penúltimo capítulo da obra. Em sua pesquisa de doutorado, a autora propôs-se a investigar processos de politização de corpos grávidos, questionando como operam determinados discursos e imagens veiculados em uma revista de publicação nacional (Pais e Filhos) em tais processos. Em consonância com autores como Barthes, Joly e Santos e, partindo da premissa de que as imagens são produtoras e veiculadoras de conceitos e saberes, Schwengber procurou destacar as relações de poder que as imagens produzem no contexto da referida revista. De modo semelhante a outros textos desta obra, as análises da autora retomam teorizações foucaultianas, como fica visível no entendimento que traça sobre categorias tais como poder, enunciado e a priori histórico.

O texto que encerra a obra, de autoria de Thiago Ranniery de Oliveira, destaca, apoiado em autores como Deleuze e Guattari, a cartografia como ferramenta metodológica para produção de pesquisas em educação. Em especial, o intuito do autor era cartografar as produções do dramaturgo Antonin Artaud, objetivando produzir conceituações para um currículo na área de artes. A descrição do caminhar metodológico com a ferramenta da cartografia pode ser comparada a uma coreografia na qual os passos são descritos por Oliveira como movimentos. Explica o autor, a partir de Deleuze, que a cartografia trata, pois, de uma inevitável coreografia do desassossego, tendo em vista que a pesquisa em educação tem a função de atualizar a potência de uma vida.

Compreendemos que a obra Metodologia de pesquisas pós-críticas em educação apresenta ao leitor modos de produzir e constituir pesquisas na contemporaneidade. Tais investigações permitem (e exigem) do pesquisador um "fazer inventivo", no qual diversificadas ferramentas metodológi- 
cas poderão ser coordenadas e utilizadas em consonância com a aproximação/problematização do objeto de sua investigação e, ainda, com as próprias perspectivas teóricas elencadas. Logo, nesse âmbito investigativo, a ação metodológica do pesquisador lembra as palavras do poeta espanhol Antonio Machado, quando afirma que se hace el camino al andar. Temos certeza de que os exemplos metodológicos apresentados na obra em questão poderão contribuir para a constituição de potentes trajetórias investigativas no campo da educação.

NOTA

1 O autor analisa músicas dos grupos Cavaleiros do Forró, Aviões do Forró, Calcinha Preta e Banda Magnificos, denominando-os como exemplos do estilo "forró eletrônico".

Recebido em: 24/06/2013

Aprovado em: 08/11/2013

Contato:

Universidade Federal do Rio Grande do Sul

Faculdade de Educação

Prédio 12201

Avenida Paulo Gama, s/n

CEP 90046-900

Porto Alegre | RS | Brasil 